Fecha de recepción: febrero 2019 Fecha de aceptación: julio 2019 Versión final: noviembre 2020

\section{Ritmo y Velocidad en Videojuegos. La Evolución Narrativa y Bloques de Interacción componentes claves de los videojuegos de plataforma}

Patricio A. León C. *

Resumen: Este artículo trata acerca de la introducción de nuevos conceptos y sus implicaciones frente al diseño, desarrollo e investigación de los juegos de video. El análisis y entendimiento de estos conceptos permite a los interesados en el tema explorar nuevas características frente a la investigación de los videojuegos como estructuras con narrativa y bloques de interacción, entidades conceptuales que permiten definir a los videojuegos como tal.

Palabras clave: Videojuegos - Narrativa - Jugabilidad - diseño de niveles - bloques de interacción - videojuegos de plataforma.

[Resúmenes en inglés y portugués en la página 128]

${ }^{(*)}$ Ingeniero en Diseño Multimedia, Universidad Alfredo Pérez Guerrero, Ecuador. Magister en Diseño, Universidad de Palermo, Argentina.

La narrativa y la jugabilidad son dos términos de interés utilizados con frecuencia al hablar de videojuegos, entender sus estructuras y enfocarlos desde nuevas perspectivas permite a los diseñadores e investigadores obtener nuevos núcleos conceptuales con los que se puede trabajar en la investigación y desarrollo de videojuegos.

En este documento se desarrolla un enfoque acerca de la narrativa y sus características, se da a conocer la definición de jugabilidad y su importancia en el diseño de niveles de los videojuegos y se pone en consideración del lector los conceptos de ritmo y velocidad en videojuegos.

Los conceptos de ritmo y velocidad en los videojuegos permiten a los interesados en el tema desentrañar varias ramas de estudio acerca de los videojuegos, en el presente documento se analizó su relación respecto a la destreza de los jugadores, la clasificación de videojuegos y el reto implementado en estos. 


\section{Enfocando la narrativa en videojuegos}

La narrativa y la jugabilidad se utilizan para hablar de varias características que puede presentar un videojuego, sin importar el género o el tipo de juego al que se refiera, diseñadores, desarrolladores, investigadores e incluso prensa especializada en la industria de los videojuegos utilizan estos conceptos.

Según Egenfeldt et al. (2016), en su libro Understanding Videogames, suelen existir dos grupos dentro de los estudios formales a los videojuegos propiamente dichos, los narralogistas y los ludologistas, estos grupos difieren entre sí respecto a cuál de estos enfoques merece más atención de análisis.

Los ludologistas están a favor de estudiar la jugabilidad y los sistemas de reglas dentro de los juegos, la narrativa para este grupo de personas constituye una trampa de estudio. En contraposición, los narralogistas enfocan sus esfuerzos al estudio de la narrativa en los videojuegos, aspecto que consideran el más importante al momento de analizar estas obras (p.28) La aproximación de los narralogistas en su fundamento original puede considerarse un tanto exagerada al descartar elementos importantes que definen a los videojuegos, como las mecánicas y la jugabilidad, componentes claves para separar el concepto de videojuegos frente a otros medios, como el fílmico.

Sin embargo, al enfocar desde otro punto de vista el entendimiento tradicional respecto a la conceptualización generalizada de la narrativa dentro de los videojuegos, se puede incursionar en nuevos senderos de investigación con repercusiones muy variadas, referente a las aplicaciones prácticas que se puede tener al utilizar este nuevo enfoque.

En un aspecto tradicional, la narrativa en videojuegos suele expresarse como un sustituto de las palabras historia o relato y en varias ocasiones se la describe como un resumen generalizado de los eventos que le ocurren a un personaje de videojuegos en su travesía, desde que es presentado o puesto en las manos del jugador hasta que logra terminar la trama principal de un videojuego.

Un mejor enfoque de lo que significa la narrativa en videojuegos se presenta cuando se la comprende como: la cadena de eventos conectados que crean una historia. (Egenfeldt et al., 2016, p.28).

En el sentido expuesto en este trabajo, es preciso señalar que la narrativa en videojuegos no corresponde precisamente a la historia editada o destacada a la que se hace referencia normalmente al momento de hablar de juegos de video. En su lugar, esta narrativa corresponde a absolutamente todos los eventos que le ocurren al personaje en pantalla.

Lo anteriormente expuesto ha sido analizado desde el punto de vista de conocidos videojuegos de plataforma publicados entre los años de 1985 y 1992, obras que nos han acompañado desde la consolidación de industria de los videojuegos, algunos ejemplares de esta época son Super Mario Bros, Sonic the Hedgehog o Megaman.

Como si de una obra musical se tratara, un videojuego se puede ejecutar de distintas maneras según quien lo interprete, unas veces puede ser percibido como una versión rápida, mientras que en otras ocasiones corresponderá a una interpretación lenta.

Con esta analogía en cuenta, se introduce así el concepto de ritmo de juego. Dicho ritmo se representa en un número que puede ser calculado al contabilizar todos los eventos que le ocurren al personaje principal durante una partida de juego. 
La determinación del ritmo de juego como se lo ha definido puede servir para tener una noción general de la narrativa de un videojuego de plataformas determinado. Estos datos numéricos pueden ser comparados de distintas maneras y con diferentes criterios para obtener datos referenciales en cuanto al diseño de estas obras e incluso respecto al rendimiento de un jugador o grupo de jugadores en relación con un videojuego de plataformas. De la misma forma, los ludologistas hacen hincapié en el estudio de la jugabilidad dentro de los videojuegos, este concepto es muy importante al momento de definir a los juegos de video como tal.

\section{Jugabilidad y diseño de niveles}

La jugabilidad es un término empleado en el diseño y análisis de videojuegos, describe la calidad del juego en términos de sus reglas de funcionamiento y diseño. Se refiere a todas las experiencias de un jugador durante la interacción con este tipo de sistemas.

Para el famoso diseñador de videojuegos Sid Meier (2012), "La jugabilidad es una serie de decisiones interesantes". La jugabilidad es por ende el alma de todo videojuego y el concepto diferenciador de estos medios interactivos (González, 2010, p.150).

Para Salen y Zimmerman (2003), la jugabilidad ronda en torno a la experiencia de usuario, y la describe como el hecho de experimentar un juego.

Se puede visualizar que el término jugabilidad abarca muchos senderos conceptuales y puede ser analizado desde varias perspectivas que permiten obtener características referentes a la satisfacción de usuario. Sin embargo, para darle un enfoque práctico y de diseño, es necesario destacar la relación entre jugabilidad y el llamado diseño de los niveles o escenarios de juego en donde ocurre la acción y se desenvuelve la trama en conjunto con los personajes en pantalla.

Los niveles o escenarios de los videojuegos están constituidos a simple vista por una cantidad de objetos ubicados en la pantalla de juego, para Totten (2014, p.41) estos niveles deben crear experiencias basadas en algunas técnicas de construcción, un trabajo muy similar al que desarrollan los arquitectos. Totten también señala que, en un inicio los diseñadores se dejan llevar por los sentimientos al crear dichos niveles o escenarios de juego, señalando la frase "No sería genial que" (Totten, 2014, p.42) como una oración expresada al momento de crear y determinar la disposición de los objetos en el espacio, este autor dictamina una serie de herramientas que puede utilizar el diseñador para construir los niveles de un videojuego. Las proposiciones señaladas por Totten constituyen una referencia para diseñar y construir niveles de videojuegos que sean entretenidos e inmersivos para los usuarios, su análisis permite entender los sentimientos de inmersión que un diseñador debe planificar cuando desarrolla un nivel o escenario de juego.

Una vez definido que el diseño de niveles se encuentra relacionado con la jugabilidad y ésta a su vez forma parte de la experiencia de usuario, es factible relacionar las acciones que un jugador ejecuta al momento de jugar videojuegos.

Dichas acciones en un principio son realizadas con el mando de juego, joystick o control y son transmitidas como pulsos eléctricos al procesador de una consola de juegos o un computador para finalmente ser interpretadas por el código de programación de un videojuego determinado. 


\section{Ritmo y Velocidad a partir de la Narrativa y Mecánicas en los videojuegos}

Para entender el ritmo y la velocidad en los videojuegos, a continuación, se presenta la relación entre algunos términos utilizados en el desarrollo de videojuegos en la actualidad. Las mecánicas de juego tienen relación con las acciones que ejecutan los jugadores al utilizar los mandos o controles de juego y es interesante señalar que forman parte de la jugabilidad y los bloques de interacción a la vez.

Como primer argumento para señalar lo expresado en el párrafo anterior se puede decir que las mecánicas o acciones de juego son parte de la jugabilidad debido a que son un elemento fundamental de la experiencia de usuario al relacionarse con la interacción, incluso los sentimientos que experimenta cada jugador al pulsar los botones o accionar la cruceta de mando.

Como segundo argumento, se puede observar que las mecánicas o las acciones de juego están plasmadas en los códigos de programación de cada videojuego. Un personaje de videojuego puede saltar o disparar, solo si los códigos de programación lo permiten.

Por lo tanto, las mecánicas de juego al ser parte de la jugabilidad y de las reglas de juego constituyen un vínculo indispensable entre los bloques de interacción y la jugabilidad del usuario. Los bloques de interacción son un término acuñado por Salen y Zimmerman (2003, p.312) en donde se plantean como parte de las mecánicas, al decir que:

"Las mecánicas son una serie de actividades compuestas por acciones, estas pueden ser representadas por una serie de bloques de interacción. Durante un juego, las mecánicas pueden formar patrones debido a sus repeticiones que se manifiestan en experiencias o jugabilidad."

Dichas mecánicas pueden ser analizadas a favor del estudio del diseño de videojuegos. Su observación conlleva a obtener datos acerca de las estructuras de los videojuegos, como la percepción de vértigo, la cual, para un entendimiento generalizado, se puede expresar como la velocidad con la que un usuario ejecuta las acciones frente a un videojuego.

Las mecánicas de juego y en consecuencia los bloques de interacción son tan variados como juegos existan, por lo que para poder reflexionar sobre las mismas se ha decidido hacer un análisis global que permita observar el panorama general.

Para obtener datos de interés en pro del diseño o la investigación, se ha planteado medir el promedio de acciones ejecutadas por los jugadores, durante una serie determinada de partidas en varios juegos de plataforma reconocidos.

Esta medición permite construir una matriz de datos con la que se puede comparar y obtener información de relevancia en relación con la unidad de análisis denominada bloques de interacción y por ende las mecánicas de juego.

Una vez definidos estos importantes conceptos frente al análisis y diseño de videojuegos, hablar de narrativa y mecánicas de juego como núcleos conceptuales permite definir a estas obras multimediales como entidades poseedoras de ritmo y vértigo respectivamente. La siguiente imagen permite expresar de manera general la relación entre los conceptos expresados: 


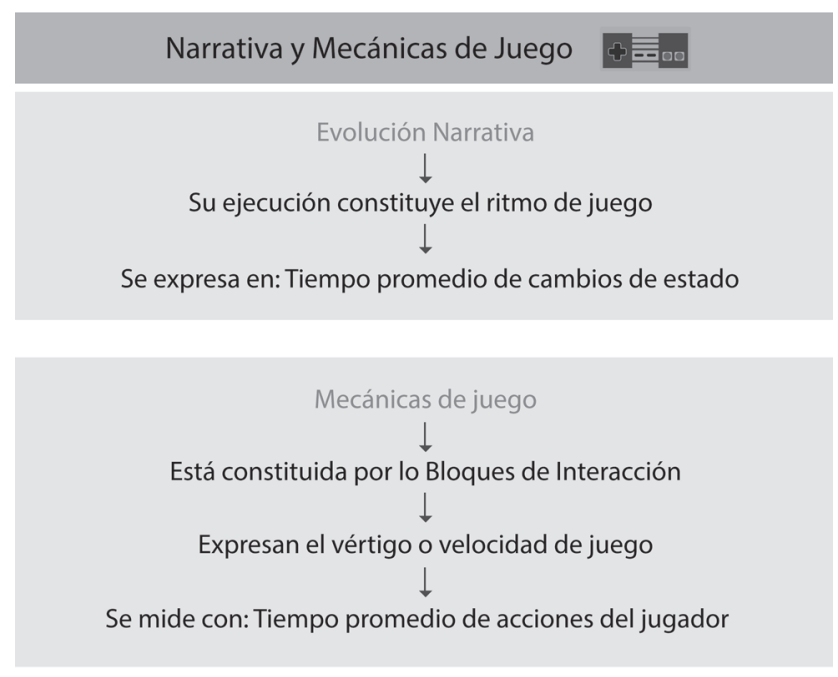

Figura 1. Relaciones entre narrativa y mecánicas de juego. Fuente: Elaboración propia.

El entrelazar lo expresado en datos numéricos, permite al diseñador o investigador comparar de manera clara y precisa el ritmo y la velocidad en los videojuegos.

El análisis de estos datos posibilita a las personas interesadas incursionar en nuevos desarrollos de videojuegos, en los que se requiera establecer un ritmo y velocidades predefinidos, adicionalmente al comparar videojuegos similares, se puede obtener indicios y caminos de investigación frente a la noción de la destreza o habilidades de los jugadores en un videojuego dado, incluso crear nuevas clasificaciones de videojuego de acuerdo con sus ritmos y velocidades.

Desde otra perspectiva, respecto al análisis de los conceptos planteados y frente a un contexto histórico, el interés por develar las estructuras con las cuales se construyeron los primeros videojuegos permite dar luz a nuevos proyectos. Si el interés es diferenciarse o construir proyectos similares a estos videojuegos clásicos, es factible que el entendimiento de la evolución narrativa y los bloques de interacción sirvan como una pauta para lograr obtener resultados según sea requerido.

Egenfeldt et al. (2016, p.28 - 29), plantea varias cuestiones acerca de los estudios en videojuegos, entre estas puntualizan:

“Cómo deberían lidiar los estudiantes de videojuegos cuya investigación se centra en un tipo de análisis con la existencia de otros tipos de análisis? ¿Es necesario en todos los casos abordar todas las perspectivas del fenómeno de los videojuegos? ¿Cuán importante es jugar estos videojuegos como investigador?” 
Para algunas de las cuestiones enunciadas por Egenfeldt et al., este documento plantea la existencia de la narrativa y la jugabilidad como medidas que permiten enfocar nuevos análisis, ayudando al encargado de su diseño o investigación, dimensionar el alcance de su proyecto de mejor manera.

\section{El reto como propiedad de la narrativa en videojuegos}

El entendimiento de la narrativa permite obtener nuevas propiedades respecto de esta si se la comprende como una sucesión de eventos continua, y al clasificarla con parámetros positivos y negativos, el investigador da cuenta de la relación entre esta estructura y los niveles de frustración que pueden existir en a la ejecución de un determinado videojuego y su respectivo usuario.

La determinación de esta polaridad positiva y negativa, se la denomina como, cargas de la narrativa, y constituye una manera por la cual el diseñador puede intervenir en la creación de experiencias de usuario al desarrollar nuevos niveles o escenarios de juego.

Los niveles en las denominadas cargas de la narrativa están inversamente relacionados a los sentimientos de frustración experimentados en un videojuego.

Es decir que, mientras mayores cargas positivas tenga la narrativa, menores serán los niveles de frustración del usuario, mientras que, a mayores niveles de frustración que se experimente es muy probable que las cargas de la narrativa sean muy negativas. Lo expresado permite construir la siguiente gráfica relacional:

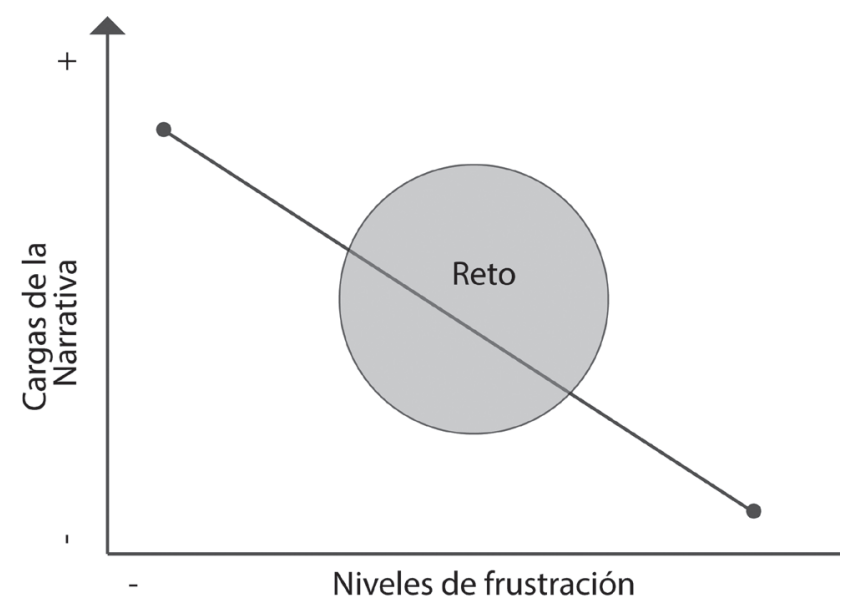

Figura 2. Cargas de la narrativa vs niveles de frustración en los videojuegos de plataformas. Fuente: Elaboración propia. 
El gráfico planteado de cargas de la narrativa vs niveles de frustración presenta la relación que se crea respecto al reto en el diseño de niveles en los videojuegos. El reto está presente en el balance entre las cargas de la narrativa y los niveles de frustración experimentados por los usuarios y podría ser manipulado y diseñado previamente en relación con el desarrollo de un videojuego.

Para un mejor entendimiento de esta conclusión, en la ejecución de un videojuego, las cargas de la narrativa se consideran positivas al momento que le ocurren acciones relativamente beneficiosas para el progreso de un personaje de videojuegos en pantalla, por ejemplo cuando gana una habilidad o derrota a un enemigo, por lo contrario, las cargas de la narrativa son negativas cuando los eventos en pantalla afectan directamente el avance o progreso del personaje y por ende del jugador, por ejemplo es alcanzado por un proyectil o cae en un abismo y muere.

Las cargas de la narrativa y su relación con los niveles de frustración son referenciadas por Totten (2014) al expresar que:

"Los diseñadores de videojuegos y los arquitectos reconocen la utilización de los instintos de supervivencia de la humanidad como una clave para un diseño placentero" (p.204)

Por lo tanto, es importante señalar que, en una cadena de producción de videojuegos, la correcta implementación del reto recae en los procesos de diseño y desarrollo, sin embargo, es posible regular su influencia en la llamada fase de pruebas, donde los responsables respectivos tienen un trabajo muy necesario, documentando todos los niveles de frustración experimentados por un grupo de jugadores.

Los diseñadores, desarrolladores e investigadores de videojuegos pueden hacer referencia a los conceptos presentados anteriormente como una nueva perspectiva para referirse a estas obras desde sus núcleos conceptuales en relación con lo que se ha descrito hasta el momento respecto a la narrativa, jugabilidad y mecánicas de juego.

Ampliar los conceptos planteados y profundizar en su entendimiento permitirá descubrir y señalar nuevas formas de ver a los videojuegos desde perspectivas más objetivas, creando nuevas formas de clasificarlos ya sea por su ritmo o velocidad. Adicionalmente permite tener indicios respecto a la forma de medir la habilidad de los usuarios al jugar un videojuego, considerando que hoy en día jugar videojuegos se ha establecido como un deporte en muchos países.

\section{Lista de Referencias bibliografía}

Egenfeldt, N., Heide, J. y Pajares, S. (2016). Understanding video games: The essential introduction. Nueva York: Routledge.

Meier, S. (2012). Interesting decisions. Recuperado de https://www.gdcvault.com/ play/1015756/Interesting

Salen, C. y Zimmerman, E. (2003). Rules of play. Londres: The MIT Press. 
González, J. (2010). Jugabilidad: Caracterización de la experiencia del jugador en videojuegos. Universidad de Granada. España.

Totten, C. (2014). An Architectural approach to level design. Estados Unidos: CRC Press. Arnheim, R. (1995). Arte y percepción visual. Madrid: Alianza Forma.

Crossley, K. (2016). Character design: From the ground up. Estados Unidos: CRC Press.

Dewinter, J. (2015). Influential video game designers: Shigeru Miyamoto.

Kent, S. (2016). La gran historia de los video-juegos. España: Ediciones B.

Mark, J., Perron, W. y Perron, B. (2003). The video game theory reader. Estados Unidos: Routledge.

\begin{abstract}
This article talks about the introduction of new concepts and its implications in design, development an investigation of videogames. The analysis and understanding of these concepts allow to the interested on these subjects to explore new characteristics related to the videogame research as structures with narrative and interaction blocks, conceptual entities that allow to define videogames as such.
\end{abstract}

Keywords: Videogames - Narrative - Gameplay - level design - blocks of interaction - platformer games.

Resumo: Este artigo fala sobre a introdução de novos conceitos e suas implicações para o design, desenvolvimento e pesquisa de videogames. A análise e compreensão desses conceitos permite que os interessados no assunto explorem novas características diante da investigação de videogames como estruturas com narrativas e blocos de interação de entidades conceituais que permitem definir videogames como tal.

Palavras chave: Videogames - narrativa - jogabilidade - design de níveis - blocos de interação - jogos de plataforma.

[Las traducciones de los abstracts fueron supervisadas por el autor de cada artículo] 